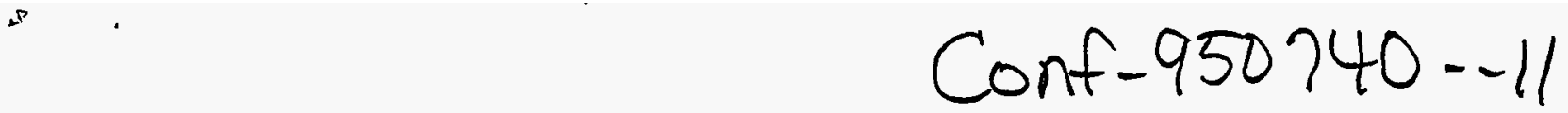

\title{
APPLICATION OF FUZZY TECHNOLOGY TO RISK-BASED DESIGN AND DECISION PROBLEMS
}

\author{
Michael E. Senglaub, Ph.D \\ System Engineering \& Special Projects \\ Sandia National Labs, \\ Albuquerque, NM \\ e-mail: mesengl@sandia.gov \\ A. Terry Bahill, Ph.D. \\ Department of Systems and Industrial Engineering \\ University of Arizona \\ Tuscon, $A Z$ \\ e-mail: terry@SIE.Arizona.EDU
}

\begin{abstract}
A study was undertaken to assess the impact of employing fuzzy technologies in areas of complex weapon system design. The technology was examined for use in a life-cycle cost exercise with the objective of providing a foundation from which to make service life assessments and recommendations on future weapon systems. The issues associated with this problem can be highly subjective and often exhibit a high degree of functional as well as variable uncertainty, ambiguity and noise. The study demonstrated that there is a potential role for the technology, but only in a hybridized environment not as a stand-alone solution methodology.
\end{abstract}

\section{INTRODUCTION}

The activities and effort described in this study are being performed as part of the Department of Energy(DOE) Defense Program (DP) activities in Center 5100 at Sandia National Laboratories in Albuquerque New Mexico. The problem being addressed involves the assessment of an "optimal" design life for use in weapon system design activities. This is part of the larger stockpile stewardship responsibility that exists in the DOE defense complex. This responsibility extends to the utilization, design, maintenance, dismantlement, and safety of systems in this stockpile. A manifestation of these responsibilities is to provide timely, cost-effective systems that satisfy all the needs of the nation. The analysis to follow assumes cost as one metric in assessing optimal system design life.

We find that new requirements are being imposed on old systems, that technology used to produce these sys- tems is disappearing, and that engineers knowledgable in their form and function are retiring or moving on to other responsibilities. The full slate of problems we are faced with include reducing the life-cycle cost of these systems, shortening the design and production cycle times, and for the near term retaining a design and production capability. The simple belief is that a reduction in programmatic cost can be realized by significantly increasing the design or service life of weapon systems currently in stockpile. A detailed life-cycle cost analysis employing modern optimization technologies might answer the problem of optimum design life, but the broader scope of issues and their lack of definitive functionality could not easily or defensibly be addressed with these technologies.

The fuzzy technology has been around for some time, but has recently gained exposure, principally in the areas of process and control engineering. A number of attributes of the fuzzy technologies struck us as a means for addressing issues in the "gray" areas of technical analysis. Characteristics of a fuzzy model (Cox, 1994) include (1) imprecise control parameters, (2) a multiple number of potentially conflicting or elastic relationships, (3) inherent uncertainties in the control structure as well as a classical probabilistic result, and (4) the problem being addressed is highly complex, poorly understood and/or nonlinear. These characteristics capture much of the problem we are faced with assessing optimum design for our weapon systems.

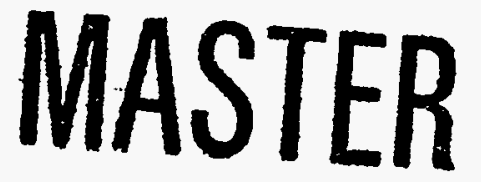

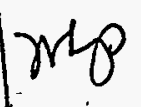

DISTRIBUTION OF THIS DOCUMENAT IS UNELINTED FEB 1 \& 1995 


\section{DISCLAIMER}

This report was prepared as an account of work sponsored by an agency of the United States Government. Neither the United States Government nor any agency thereof, nor any of their employees, makes any warranty, express or implied, or assumes any legal liability or responsibility for the accuracy, completeness, or usefulness of any information, apparatus, product, or process disclosed, or represents that its use would not infringe privately owned rights. Reference herein to any specific commercial product, process, or service by trade name, trademark, manufacturer, or otherwise does not necessarily constitute or imply its endorsement, recommendation, or favoring by the United States Government or any agency thereof. The views and opinions of authors expressed herein do not necessarily state or reflect those of the United States Government or any agency thereof. 


\section{DISCLAIMER}

Portions of this document may be illegible in electronic image products. Images are produced from the best available original document. 


\section{FUZZY TECHNOLOGY DESCRIPTION}

This short section provides a perspective of the elements characteristic of the "fuzzy" technologies which provide an engineer with another tool that can be used to solve increasingly complex design, decision, and analysis problems. The objective of this work and this section in particular is to evaluate a technology for use by engineers in solving complex problems and not to evaluate the fundamental theoretical aspects of the technology (This would be well beyond the scope of this paper.). The technology provides the engineer with another "mathematical construct" for mapping design or analysis variables to a solution space. Function theory defines operations and set characteristics which permit us to map variables within an infinitely continuous real space. Boolean algebra provides us with the ability to perform relational mappings in discrete space. It appears that the fuzzy technologies provide us with a capability to perform a modified form of mapping within a variable space of our definition and design. The mathematics provide us with the operators and a set of requirements for the variable space.

The essence of "fuzzy" technology is the unique nature of its underlying set theoretic characteristic. In classical functional theory we can immediately interpret the validity or truth of a solution variable given the independent parameter values. For example, an ideal gas law mapping between pressure and specific volume, each set to zero, and a temperature value of $1.0 \times 10^{6}$ is known to be invalid. In the area of fuzzy technologies this result must be assessed before a degree of validity or truth can be ascertained. It is the set theoretic characteristic of this technology that enables and requires the follow-on assessment.

\section{MODEL DEVELOPMENT}

In order the assess the utility of "fuzzy" technology for use in the design life optimization problem, a $\mathrm{C}++$ code was written that captured the fundamental characteristics of the technology. The code was restricted to a limited number of operator concepts, rule generality, and defuzification methodologies. The objective of the code was to provide an operational test bed to gain some experience with this approach to solving design problems and to provide the framework from which the assessments on the utility of the technology could be made.

$\mathrm{CH}$ was chosen as the language tool because of past experience in the language and the ability to develop rapid prototypes of new algorithms. The operators were initially limited to Zadah's rules of fuzzy set com- binatorics and a subset of defuzification methodologies. The observed nonlinearity of the problem indicated that some variables were solutions to a subset of the model parameters. This required a rather complex control structure for an evaluation algorithm.

\subsection{Validation}

There does not appear to be formal mathematical theorems which can be used to validate a model based on fuzzy technologies. One reference (Carraanza, 1992) provided an interesting approach for assessing the stability of fuzzy controllers. This validation methodology is well suited for the controller situation since it is possible to delineate acceptable states for the fuzzy controller. Validating fuzzy technologies in a system design effort is more difficult since we may only be able to bound the problem. The method does not appear to lend itself to assessing the accuracy of the solutions which is the validation problem that we are faced with.

A solution to the problem of validation is to assess the accuracy of the model on a problem of comparable characteristics, and by inference postulate the accuracy of a models. Since problems in system design are expected to be highly non-linear it was decided that a fuzzy interpretation to the ideal gas law could be used in a validation process:

$$
T=(P \cdot v) /(n \cdot R)
$$

Table 1 provides a listing of the initial model variables and the semantic levels or fuzzy sets that represented the descretized levels associated with the model variables.

Table 1: Validation variables, hedges, and linguistic sets

\begin{tabular}{|l|l|l|l|l|}
\hline \multicolumn{1}{|c|}{$\begin{array}{l}\text { Domain } \\
\text { Variable }\end{array}$} & Hedges & \multicolumn{2}{|c|}{ Sets } \\
\hline \hline $\begin{array}{l}\text { TEMPERA- } \\
\text { TURE }\end{array}$ & VERY & HIGH & $\begin{array}{l}\text { MOD- } \\
\text { ERATE }\end{array}$ & LOW \\
\hline PRESSURE & & HIGH & $\begin{array}{l}\text { MOD- } \\
\text { ERATE }\end{array}$ & LOW \\
\hline $\begin{array}{l}\text { SPECIFIC } \\
\text { VOL. }\end{array}$ & & HIGH & $\begin{array}{l}\text { MOD- } \\
\text { ERATE }\end{array}$ & LOW \\
\hline
\end{tabular}

Also listed in the table are the "hedges" used in the validation problem. In fuzzy technologies, a hedge (Cox, 1994) is a technical term that represents a class of functional modifiers applied to the underlying fuzzy set membership functions. These modifiers tend to intensify or diffuse membership intensity. 
Three semantic levels were selected for each of the model variables in the problem. The membership functions selected during the initial tests were low-order linear functions. The functions for temperature are presented in Figure 1. A higher order set of membership functions was used later in the validation process and is plotted in Figure 2.

\section{Temperature Variable}

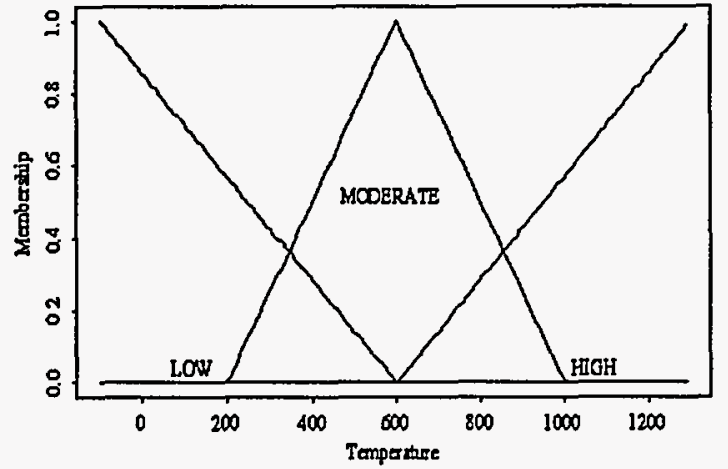

Figure 1. Linear membership functions for the temperature model variable.

Temperature Variable

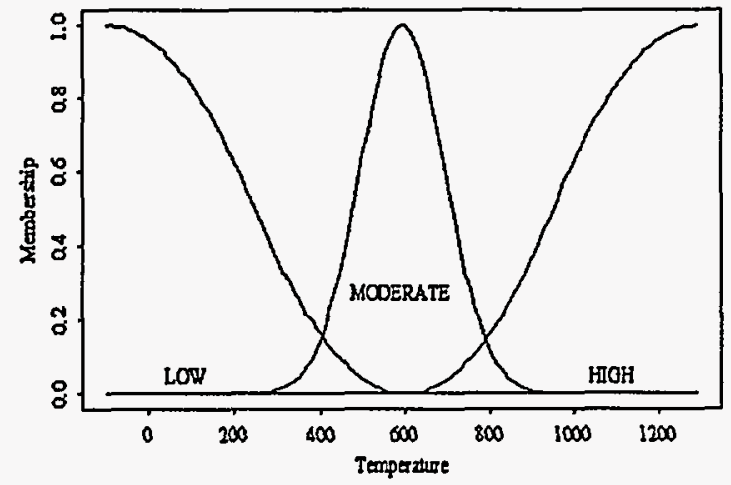

Figure 2. Nonlinear membership functions for the temperature model variable.

A very simple process was used to define the initial set of validation rules. The domain of the model variables was selected to range from $-100^{\circ} \mathrm{C}$ to $1300^{\circ} \mathrm{C}$, with a corresponding range for the pressure and specific volume. A combinatorics matrix was used to represent all the combinations of semantic levels for the independent model variables. This matrix is presented in Table 2. A fuzzy rule was written for each element of the combinatorics matrix. The rules were of the form:

if PRESSURE is LOW and SP_VOL is LOW then TEMPERATURE is VERY LOW

The initial calculations used the linear and the nonlinear membership functions in conjunction with the nine rules developed from the matrix in Table 2. The domain used for the pressure variable was 0.1 to 0.5
$\mathrm{MPa}$, while the specific volume domain ranged from 0.5 to $0.9 \mathrm{~m}^{3} / \mathrm{Kg}$.

Table 2: Rule combinatorics for solution space, temperature.

\begin{tabular}{|c|c|c|c|}
\hline & Low & Moderate & High \\
\hline Low & $\begin{array}{l}\text { VERY } \\
\text { LOW }\end{array}$ & . & $\begin{array}{l}\text { MODER- } \\
\text { ATE }\end{array}$ \\
\hline Moderate & \% & $\begin{array}{c}\text { MODER- } \\
\text { ATE }\end{array}$ & 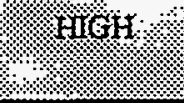 \\
\hline High & $\begin{array}{l}\text { MODER- } \\
\text { ATE }\end{array}$ & \%) & $\begin{array}{l}\text { VERY } \\
\text { HIGH }\end{array}$ \\
\hline
\end{tabular}

The results of these calculations are provided in Figures $3 A$ through 3D.

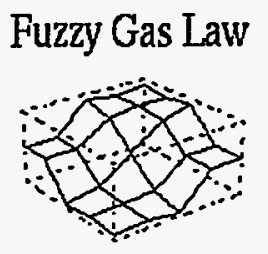

$A$
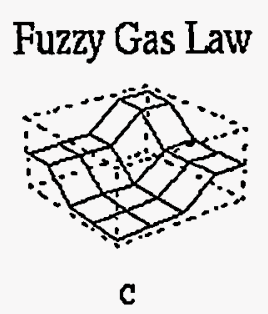

Fuzzy Gas Law

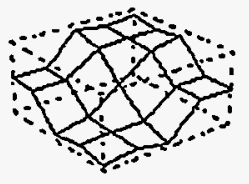

B
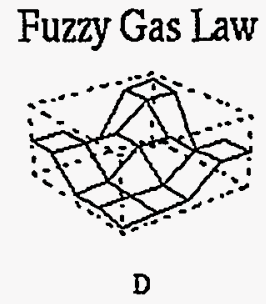

Figure 3. (A) Linear fuzzy representation of the ideal gas law. (B) Nonlinear fuzzy representation of the ideal gas law. (C) Semantic levels reduced to $\mathrm{HIGH}$ and LOW. (D) Reduced rule set.

The points of interest are the near-identical behavior between the linear and nonlinear models. This provides additional verification that the membership function shape is not a strong player in these coarsely descretized problems. The effect of using a coarser descretization of the semantic levels can be seen in Figure 3C. The results exhibit less detail than those in Figures $3 \mathrm{~A}$ and $3 \mathrm{~B}$, but the essential levels and trends associated with the underlying model have been preserved.

The last test involved reducing the rule set. The idea was to assess the possibility of using a design of experiment technique in the generation of rule sets. The rules that were removed consisted of those highlighted in Table 2. From Figure 3D, we can see that the perfor- 
mance of the modified rule set is severely degraded, especially in the regions covered by the removed rules. Further analysis needs to be conducted in order to assess "completeness" issues associated with fuzzy reasoning algorithms. It appears that a larger problem needs to be defined and a rigorous application of Taguchi techniques used in order to assess the issues of completeness that surfaced with this very simple analysis.

Tests were also exercised to assess the impact of the different defuzification algorithms used in the preliminary code. Three methods were examined: (1) the centroid method, (2) the averaged maximum method, and (3) a maximum technique that selects the leading edge of the maximum truth plateau. The centroid method is simply a weighted average over the entire solution variables' domain space. The weighting consists of the product of the domain value and the associated degree of truth. The averaged maximum method represents the weighted average of the maximum truth plateau of the solution variable. Each method produced unique results. The results in Figure 3 represent the utilization of the averaged maximum method. The centroid method provided results which most closely approximated the mean shape of the gas law. However, the results at the extremes were clearly inferior to those generated by the maximum methods. The analyses to follow will use the averaged maximum technique for defuzification.

\subsection{Preliminary Expansion}

The next test that had to be performed consisted of an expansion into the treatment of "issues." The complexity of the problem requires that a number of issues had to be resolved prior to a final solution of the problem variables. In order to test issue resolution, an additional model variable was added to the decision problem. The variable, RADIATION, was assumed to affect gas temperature directly and indirectly through the specific volume. (It should be noted that this variable is an artificial construct and was used for test purposes only.) The added influences are shown by the dotted lines in Figure 4.

The physics of this problem is non-real and has been performed merely for code validation activities. In this scenario the specific volume is determined based on a rule set relating radiation and the specific volume of the gas. Once the specific volume has been estimated via the defuzification process, another rule set was executed that performed the assessment of temperature based on the additional model variable and the rule set used for the first part of the validation process.

\section{Validation Problem}

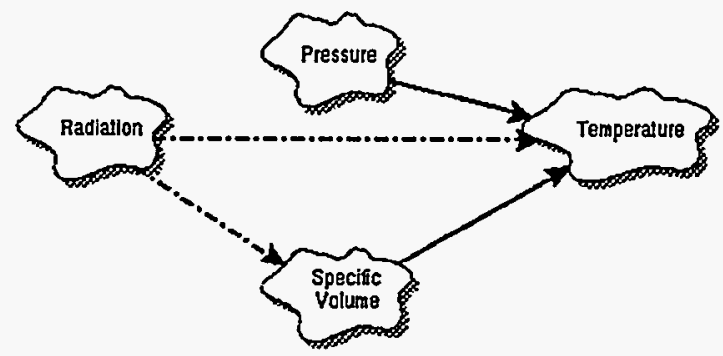

Figure 4. Influence diagram for the idealized ideal gas validation problem

\subsection{Generic Observations}

A number of fuzzy technology observations can be made at this juncture of the study. The observations pertain to (1) the number of semantic levels for use in fuzzy analysis problems, (2) the completeness of the rule set, (3) the defuzification methodologies, and (4) the order of membership functionality. The resolution of the solution variable results is directly proportional to the number of semantic levels and rules employed in the analysis. If a great deal of resolution is required increase the number of levels. It has also been observed that there may be a completeness issue associated with the implemented rule set.

Each defuzification method possesses varying degrees of suitability depending on the problem being worked. The centroid method may be appropriate for policy analyses where detail is unimportant. The maximum edge method may be best suited for use in the safety analysis arena where model conservatism is important. The averaged maximum seems to be suited best for optimization problems such as the design life problem. Finally, there appears to be an insensitivity to the functional form of the membership functions associate with the semantic levels. It appears that each situation must be assessed on its' own merits.

\section{DETAILED PROBLEM DESCRIPTION}

These last sections examine the potential for the development of a limited service-life estimation model. The objective of the model was to provide sufficient evidence of the utility or nonutility of using fuzzy technologies in the estimation of weapon system service life. As indicated earlier the performance metric identified is the life-cycle cost for a weapon system. Generic elements comprising a life-cycle costing model (Fabrycky, 1991) consist of (1) research and development costs, (2) production costs, (3) operations and maintenance sup- 
port costs, and (4) retirement and disposal costs. Figure 5 provides a high-level view of the problem being addressed. The cost components have been broken out in slightly more detail, but do not address the level of detail needed to perform a life-cycle cost analysis. The left side of the figure is an indicator of the direct effects that system service life would play in a costing model: the indirect effects are not detailed in this figure. A subset of the indirect effects are included in Figure 6.

\subsection{Information Uncertainties}

One problem that has to be considered is the different type of uncertainty associated with the model depicted in Figure 5. The uncertainty associated with the cost parameters can be attributed to variabilities in the independent variables of the model. Classical statistical techniques should be used to assess the effects of this uncertainty. The second class of uncertainty is that associated with parameters directly affected by service life and the indirect effects on the cost variables of the life-cycle cost model. This uncertainty can be classified as a functional uncertainty which is a lack of understanding of the underlying functional relationship or mapping between the independent variables and the solution variables.

It was felt that there are two generic approaches to solving this hybrid problem. One approach is to use the fuzzy technology to determine the cost associated with selected cost elements of the life-cycle cost model. The second approach is to use the fuzzy model to "modify" the cost estimates provided through a more traditional functional model. The implementation of the two approaches differed only in the addition of an extra rule, which in effect constrained the results of the predictive facet of the fuzzy model.

Indirect Service Life Cost Effects (Uimited Scope)

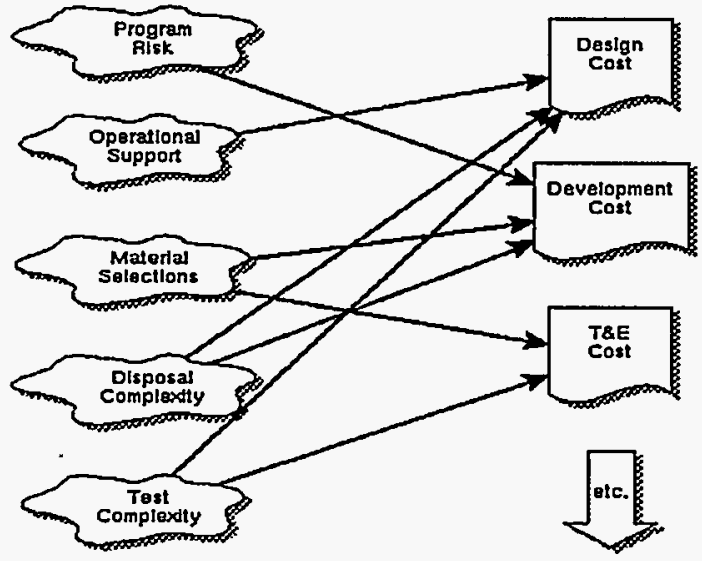

Figure 6. Indirect effects of service life.

The object of this phase of the service life activity was not to generate a solution but to assess technologies which might be employed to develop a solution. The variables selected for inclusion in this preliminary model consisted of the following: (1) "service life," (2) "engineering skills," (3) "mission complexity," (4) "program risk," (5) "development cost," (6) "test cost," (7) "operations support," (8) "materials selected," (9) "testing complexity," and (10) "disposal complexity."

Combined Analysis Model
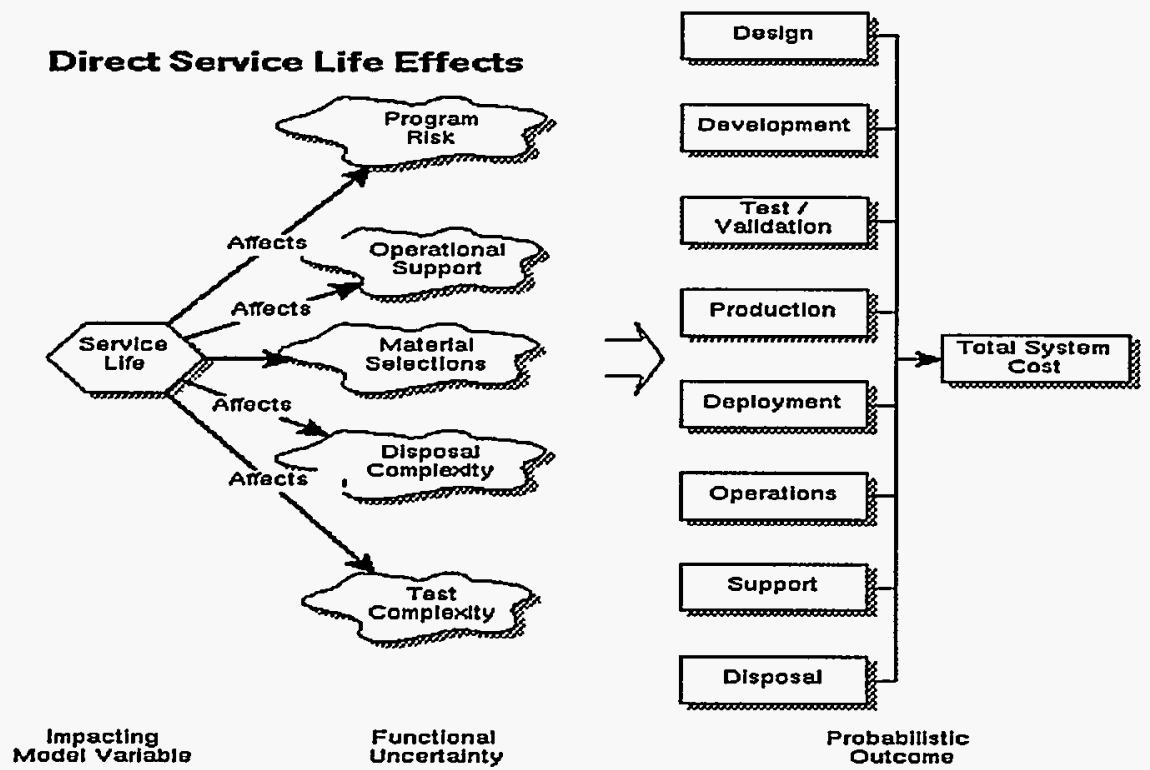

Figure 5. Service life optimization model with fuzzy and functional elements identified. 
This is not an all-inclusive list of problem space variables, and for purposes of this analysis each of the 10 variables was not considered in equal detail. Each of these domain variables was assigned either two or three semantic levels for inclusion in the model. In addition, one or two hedges were assigned to enable semantic intensification or diffusion in the problems space. The rule set used in this study is provided in the Table 3 below. The row separations correlate with the separation of the issues that had to be addressed prior to the indirect cost analyses.

The rule sets addressed the issues of (1) programmatic risk, (2) test complexity, (3) materials selection, and (4) operational support. The final two rule sets were used to solve for development and test costs. The last two rule sets contain a highlighted rule which contains only the consequent part of a standard rule predicate. It is these extra rules which were required to transition the model from a predictive algorithm to that of a proscriptive model. These rules use an "ABOUT" construct which in the technology is a fuzzified representation for a number. Thus ABOUT 5 represents the fuzzified approximation to the value 5. A number of the variables used in this model do not possess a classical measurable descriptive scale. The variables associated with "engineering skill level," or "programmatic risk" are metrics which do not possess an absolute scale. At best, the scales associated with these and similar variables can only be used in studies concerned with relative effects.

\subsection{Results Analysis}

A series of 25 cases were run to span a spectrum of service life, engineering skill levels and mission complexity. The service-life assessments ranged from 10 to 90 years. The other two variables are founded on a relative scale. Four sets of these cases were run to assess the effects of different defuzification algorithms and to assess the differences between the predictive and the proscriptive versions of the model. The results of these first set of predictive calculations is presented in Figure 7.

This figure provides a look at two of the three indepen-

Table 3: Fuzzy rule sets used in the life cycle cost feasibility study.

Rules by "issue"

if SERVCIE_LIFE is LONG and MISSION_PROFILE is COMPLEX then PGM_RISK is VERY HIGH if SERVCIE_LIFE is LONG and SKIILLS is NOVICE then PGM_RISK is VERY HIGH if SERVCIE_LIFE is SHORT and SKIILSS is HIGHLY CAPABLE then PGM_RISK is VERY LOW if SERVCIE_LIFE is NOMINAL and SKIILIS is CAPABLE then PGM_RISK is LOW if SERVCIE_LIFE is NOMINAL and SKIILS is NOVICE then PGM_RISK is SOMEWHAT HIGH

if SERVCIE_LIFE is SHORT and MISSION_PROFILE is ROUTINE then TEST_COMPLX is DECREASED

if SERVCIE_LIFE is LONG and MISSION_PROFILE is COMPLEX then TEST_COMPLX is SIGNIFICANTLY INCREASED

if SERVCIE_LIFE is NOMINAL and MISSION_PROFILE is ROUTINE then TEST_COMPLX is SOMEWHAT DECREASED

if SERVCIE_LIFE is LONG then MATERIALS is EXOTIC

if SERVCIE_LIFE is NOMINAL then MATERIALS is SOMEWHAT EXOTIC

if SERVCIE_LIFE is SHORT then MATERIALS is VERY ROUTINE

if SERVCIE_LIFE is LONG then OPS_SUPPORT is VERY HIGH

if SERVCIE_LIFE is SHORT then OPS_SUPPORT is SOMEWHAT LOW

if PGM_RISK is HIGH and MATERIALS is EXOTIC then DEV_COST is HIGH

if TEST_COMPLX is INCREASED then DEV_COST is VERY HIGH

if TEST_COMPLX is SOMEWHAT DECREASED then DEV COST is LOW

if PGM_RISK is LOW and MATERIALS is ROUTINE then DEV COST is VERY LOW

if PGM_RISK is LOW and MATERIALS is EXOTIC then DEV_COST is SOMEWHAT HIGH

if PGM_RISK is VERY LOW and MATERIALS is ROUTINE then DEV_COST is VERY LOW

then DEV_COST is ABOUT5

if MATERIALS is EXOTIC then TEST_COST is SOMEWHAT HIGH

if MATERIALS is ROUTINE then TEST_COST is LOW

then TEST_COST is ABOUT7 
dent variables that were considered in these analyses. The average maximum defuzification is far more indicative of the underlying coarseness of the semantic levels selected. The centroid defuzification method, which is a weighted average of cost over the entire domain, is less sensitive to the underlying model coarseness. As expected, increases in service life or mission complexity results in increases in system cost. In this case, system cost includes only development and test cost.

\section{Costing (Ave Max) Costing (Centroid)}
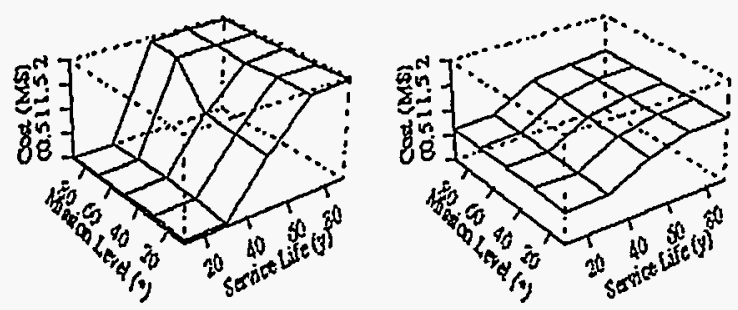

Figure 7. Results of costing analysis using "average maximum" and "centroid" defuzification.
The test runs were set up based on Taguchi's design of experiment techniques (Phadke, 1989) and as a result provide a great deal more information if statistically analyzed. Taguchi techniques involve the utilization of a design-of-experiment technique in which orthogonal arrays are used to proscribe combinations of variable settings to be used in a series of "experiments." For each combination of variable settings, a calculation or experiment is done to assess the performance of the system under consideration. Once all trials or experiments are completed, a statistical analysis can be performed which provides sensitivity information of the model or systems variables. The method also works very well in performing noise analysis calculations on system designs. The use of the orthogonal arrays preserve certain statistical properties which permit the subsequent analysis required. The results of the Taguchi analysis are provided in Figure 8.

The results of the Taguchi analysis show that "for the rule set selected for this study," service life is the most important design parameter identified in these analyses. It must be remembered that this analysis is not assess-
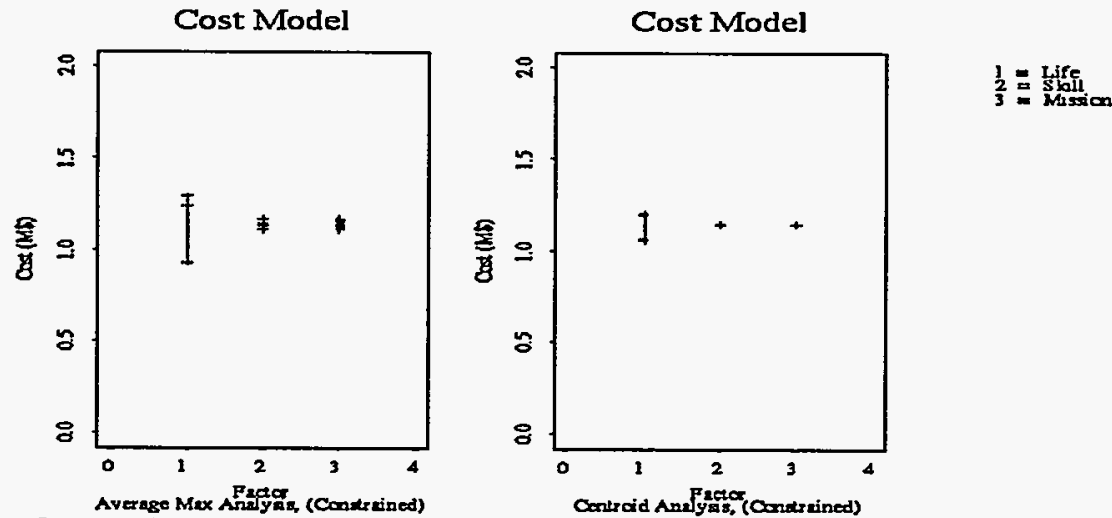

Figure 8. Results of the Taguchi analysis for the predictive fuzzy cost model.
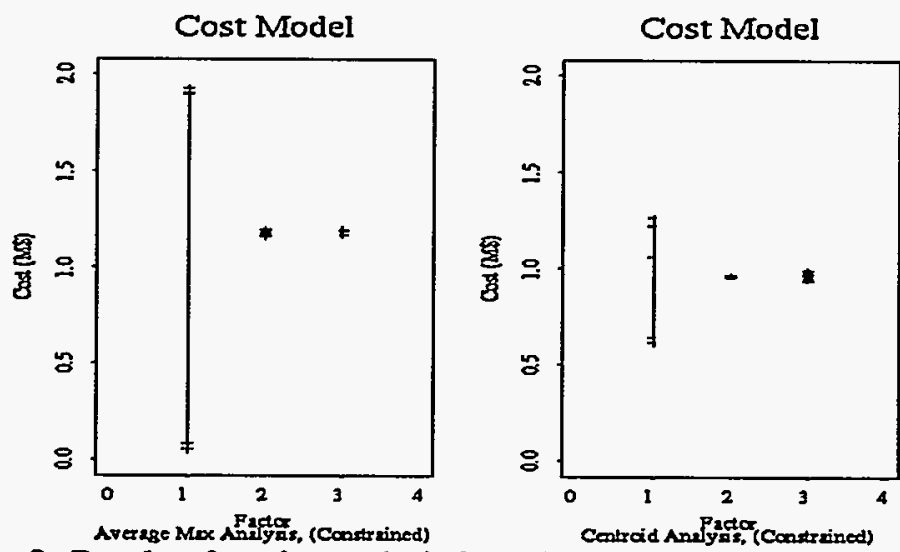

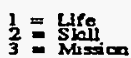

Figure 9. Results of costing analysis from the proscriptive model. 
ing parameter sensitivities as is the case in a traditional statistical analysis, but is assessing the sensitivity of the variables coupled with the rule base. A different rule base may reveal a different parametric sensitivity. It needs to be remembered that the sensitivities represent the effect that a parameter exhibits over an average of the other analysis parameters. In this case, service-life sensitivity represents the sensitivity of service life averaged over a range of values representing engineering skills and mission complexity. The figure shows that service life on the average is an order of magnitude more important than the other two parameters.

As can be seen from the results of the proscriptive model presented in Figure 9, service life is the most important parameter in the fuzzy model, but the relative importance has been severely constrained. The results fall much closer to the constrained values of $1.2 \mathrm{M} \$$, which was an arbitrarily selected fuzzy limit. Similar to the predictive model, the centroid defuzification tends to smooth the effects of the underlying semantic level coarseness.

\section{CONCLUSIONS}

The fuzzy technologies examined in this study appear to possess a degree of utility applicable to the analysis of highly complex problems that possess a significant degree of functional as well as parametric uncertainty. The technology appears to provide a unique method for constructing metrics for abstract concepts such as engineering skill level or programmatic risk. The technology provides a foundation upon which it is possible to operate with subjective and conflicting information. It seems that the optimal method of implementation of this technology is in a hybrid environment in which the technology's strengths are used to augment a traditional analysis methodology.

The fuzzy approach to solving the functionally ambiguous aspects of the life-cycle cost analysis problem appears to be appropriate when melded with traditional statistical technologies. The use of the technique in a purely predictive mode is extremely labor intensive and potentially difficult to validate on complex problems. The technology used in a proscriptive mode is ideally suited for this problem. Classical functional theory can provide the foundations from which base cases can be generated; the fuzzy technology can be used to asses the impact of uncertain issues such as new technologies, processes, missions, or environments on design issues. Fuzzy technologies have a role in the analysis of complex design problems but is not a panacea.

The models need to be refined before they can be used in a production environment and additional work needs to be performed to develop an improved interface between fuzzy technology and traditional functional methodologies. The results observed in the preliminary model verification seem to indicate that there may be issues associated with completeness. These issues of rule completeness need to be addressed to aid in the model validation process. Finally, there appears to be a unique opportunity to examine a union of fuzzy technologies and Taguchi techniques to assess the impact of rules in a model. Taguchi techniques are typically applied to problems in which parametric sensitivities are being assessed. Fuzzy technologies deal with functional uncertainty, and it might prove useful if the powerful Taguchi methodologies could be generalized and provide benefit in this technology area to assess the impact of a rule or set of rules in a model.

\section{REFERENCES}

M. Carranza, "Verifying a Knowledge-Based Fuzzy Controller," Technical Report 82, Computational Logic Inc., September, 1992.

E. Cox, The Fuzzy Systems Handbook; Academic Press, Inc.; Cambridge MA; 1994; ISBN 0-12-194270-8

W. Fabrycky, B. Blanchard, Life-Cycle Cost and Economic Analysis; Prentice-Hall, Inc.; Englewood Cliffs, NJ; 1991; ISBN 0-13-538323-4

M. Phadke, Quality Engineering Using Robust Design; Prentice-Hall, Inc.; Englewood Cliffs, NJ; 1989; ISBN 0-13-745167-9

\section{BIBLOGRAPHY}

G. Klir and T. Folger, Fuzzy Sets, Uncertainty and Information; Prentice-Hall, Inc.; Englewood Cliffs, NJ; 1988; ISBN 0-13-345984-5

B. Kosko, Neural Networks and Fuzzy Systems; Prentice-Hall, Inc.; Englewood Cliffs, NJ; 1992; ISBN 0-13611435-0

This work was supported by the United States Department of Energyunder Contract DE-AC0494AL85000. 